\title{
ADESÃO À DEMOCRACIA E EDUCAÇÃO ESCOLAR NO BRASIL (1989-2018): CONSIDERAÇÕES A PARTIR DAS TEORIAS DA LEGITIMIDADE POLÍTICA
}

\author{
JULIAN BORBA ${ }^{1}$ \\ Ednaldo Aparecido Ribeiro ${ }^{2}$
}

\begin{abstract}
RESUMO: Teorias da legitimidade possuem expectativas divergentes sobre a relação entre longevidade institucional, escolarização e apoio ao regime. Enquanto algumas defendem que a democracia equaliza os indivíduos em termos de recursos, outras afirmam a natureza estrutural da desigualdade. $\mathrm{O}$ artigo testa tais expectativas analisando os efeitos da educação escolar sobre a adesão à democracia entre 1989 e 2018. Combina dados de pesquisas de opinião de diferentes institutos nacionais e internacionais sobre o Brasil e, por meio de técnicas de análises de séries temporais e modelos logísticos, não identifica evidências de ampliação do apoio à democracia entre os brasileiros. Aponta ainda, que fatores de curto prazo interferem nas medidas de apoio e satisfação com o regime e que os efeitos da escolaridade sobre atitudes democráticas são relevantes, especialmente sobre a adesão normativa.
\end{abstract}

Palavras-chave: Democracia. Legitimidade. Educação escolar. Brasil.

\section{DEMOCRATIC SUPPORT AND SCHOLAR EDUCATION IN BRAZIL (1989-2018): CONSIDERATIONS BASED ON THEORIES OF POLITICAL LEGITIMACY}

\begin{abstract}
Theories of legitimacy have divergent expectations about the relationship between institutional longevity, scholar education and support for the regime. While some argue that democracy equals individuals in terms of resources, others affirm the structural nature of inequality. The article tests such expectations by analyzing the effects of scholar education on adherence to democracy between 1989 and 2018. It combines data from opinion polls from different national and international institutes on Brazil and, through time series analysis techniques and logistical models, does not identify evidence of increased support for democracy among Brazilians. It also points out that short-term factors interfere with measures
\end{abstract}

Este artigo foi originado da pesquisa "Mudanças e permanências nos padrões de participação política no Brasil” (1988-2013), financiado pela CAPES através do Edital PROCAD 071-2013. Processo n. 157228. Os autores também receberam financiamento do CNPq, através de Bolsas de Produtividade em Pesquisa.

1.Universidade Federal de Santa Catarina - Departamento de Sociologia e Ciência Política - Florianópolis (SC), Brasil. E-mail: julian.borba@ufsc.br

2.Universidade Estadual de Maringá - Maringá (PR), Brasil. E-mail: earibeiro@uem.brail

Editor de Seção: Adriana Dragone Silveira 
of support and satisfaction with the regime and that the effects of scholar education on democratic attitudes are relevant, especially on normative adherence.

Keywords: Democracy. Legitimacy. Scholar education. Brazil.

\title{
APOIO A LA DEMOCRACIA Y LA EDUCACIÓN ESCOLAR EN BRASIL (1989-2018): CONSIDERACIONES BASADAS EM TEORIAS DE LA LEGITIMIDADE POLÍTICA
}

\begin{abstract}
RESUMEN: Las teorías de la legitimidad tienen expectativas divergentes sobre la relación entre longevidad institucional, educación escolar y apoyo al régimen. Mientras algunos sostienen que la democracia iguala los individuos en términos de recursos, otros afirman la naturaleza estructural de la desigualdad. El artículo pone a prueba dichas expectativas analizando los efectos de la educación escolar en la adhesión a la democracia entre 1989 y 2018. Combina datos de encuestas de opinión de diferentes institutos nacionales e internacionales sobre Brasil y, a través de técnicas de análisis de series de tiempo y modelos logísticos, no identifica evidencia de un mayor apoyo a la democracia entre los brasileños. También señala que factores coyunturales interfieren con las medidas de apoyo y satisfacción con el régimen y que los efectos de la escolarización en las actitudes democráticas son relevantes, especialmente en la adherencia normativa.
\end{abstract}

Palabra-clave: Democracia. Legitimidad. Educación escolar. Brasil.

\section{Introdução}

$\mathrm{D}$ esde o seminal estudo de David Easton na década de 1960, legitimidade tem sido definida como o apoio conferido pela cidadania a um regime político. Analiticamente, tal apoio se estabelece a partir de uma dupla dimensão: no primeiro nível (apoio difuso), estariam os valores básicos ligados à aceitação abstrata dos princípios fundamentais do regime político ${ }^{1}$. O segundo nível seria composto por fenômenos específicos (apoio específico), ligados às avaliações acerca do funcionamento concreto das instituições que compõem o regime político e o desempenho dos seus operadores, "aqueles que são responsáveis pelas ações cotidianas tomadas em nome de um sistema político” (EASTON, 1967).

O primeiro nível, portanto, enfatiza uma dimensão normativa e pode estar relacionado a processos prolongados de socialização política dos indivíduos que, submetidos a experiências no interior de instituições como família, escola e trabalho, internalizariam valores de apoio ou rejeição ao sistema e suas partes constituintes.

É a continuidade na incorporação e na alteração de valores e crenças que nos remete à segunda dimensão, pois o apoio pode ser afetado, em curto prazo, por desempenhos conjunturais, positivos ou negativos, por parte das instituições e das lideranças políticas. Nesse caso, devemos considerar os cidadãos como capazes de avaliar tais desempenhos e, conscientemente, apoiar ou rejeitar esses objetos políticos isoladamente ou o sistema político como um todo em razão dos benefícios que recebem.

Essa complexa relação entre os efeitos de curto e longo prazos sobre a legitimidade democrática tem sido uma das dimensões centrais na pesquisa sobre o tema. Na literatura, existem expectativas divergentes sobre a relação entre longevidade institucional e democracia. De um lado, existe a expectativa de que, à medida que as gerações vão sendo socializadas sob um regime democrático, suas bases de apoio se ampliem, 
criando um "legado". Espera-se ainda que esse legado se torne parte da cultura política, equalizando os indivíduos, de modo que os efeitos, por exemplo, das desigualdades de recursos (econômicos, cognitivos, associativos) venham a ser reduzidos ou mesmo eliminados à medida que a democracia avança no tempo (MCCOY, 2000; KRISCHKE, 2001). Por outro lado, outras abordagens destacam que a desigualdade de recursos é estrutural à democracia. Além disso, sociedades com maiores legados exigem maiores recursos cognitivos dos indivíduos, pois, ao ampliarem a inclusividade e a contestação (DAHL, 2005), trazem novas exigências ao cidadão em termos de habilidades cívicas necessárias para a convivência política.

Tomando como base empírica o caso brasileiro, buscaremos problematizar e testar empiricamente tais expectativas, especialmente por meio da análise dos efeitos da educação ${ }^{2}$ sobre a adesão à democracia ao longo do tempo compreendido pelo início da vigência da Constituição de 1989 até 2018.

Os dados que serão utilizados derivam de um esforço da equipe do projeto Procad/CAPES ${ }^{3}$ de compilação de um banco de dados com informações de diferentes surveys nacionais e internacionais sobre variadas medidas de atitudes dos brasileiros em relação à democracia como forma de governo e a alguns dos seus princípios fundamentais (participação, liberdade de expressão, independência dos poderes, entre outros). Esse banco integrado cobre o período de 1989 a 2018, compreendendo, portanto, toda a experiência democrática recente em nosso país.

Inicialmente, abordaremos de maneira descritiva o fenômeno da adesão, utilizando técnicas de análise de séries temporais para identificar a trajetória de alguns indicadores selecionados. Nossa intenção, nessa primeira fase, é captar a tendência geral de evolução dessas medidas, mais especificamente avaliando se as oscilações de fato apontam para elevações/reduções ou se estamos lidando com uma série estacionária nesse intervalo de tempo.

A análise da relação entre educação e atitudes relativas à democracia começa na segunda etapa da análise, quando empregamos modelos multinível para identificar possíveis interações de aspectos ligados ao contexto democrático e econômico nacional das últimas décadas com os efeitos da escolaridade formal.

Por fim, esse relacionamento é explorado com maiores detalhes pelos modelos logísiticos, que permitem identificar alterações nos efeitos da escolaridade ao longo do tempo. Os coeficientes encontrados em cada um dos anos são, finalmente, tomados como medidas dependentes na análise de séries temporais.

\section{Legitimidade: Legado, Desempenho, Humor e Educação}

Em 1965, David Easton publicou a obra A Systems Analysis of Political Life, que se tornou referência importante para o debate empírico sobre legitimidade democrática. Sua proposição é de que a sobrevivência de um sistema político depende do seu apoio pela sociedade, o qual se expressaria de diferentes modos (apoio difuso e apoio específico) e objetos (comunidade política; regime político e autoridades políticas).

Apesar de Easton não ter propriamente operacionalizado sua teoria da legitimidade empiricamente, grande parte dos estudos sobre o tema foi desenvolvida na tradição por ele iniciada. Os estudos posteriores foram, em grande parte, direcionados 1) ao diagnóstico da situação das democracias em termos de legitimidade; e 2) aos desenvolvimentos teóricos e metodológicos em torno do conceito de apoio político, especialmente às relações entre os apoios difuso e específico, bem como seus determinantes.

A partir dos anos 1990, os pesquisadores passaram a empregar noções multidimensionais de legitimidade, sendo que autores como Norris (1999), Dalton (2007) e Booth e Seligson (2009) desenvolveram contribuições originais na reformulação da concepção eastoniana. Nessa perspectiva, cada objeto político é sujeito tanto ao apoio difuso quanto ao específico (TORCAL; MONCAGATTA, 2011). 
No presente artigo, buscamos avançar nessa direção, desvendando as bases da legitimidade democrática e usando, para tanto, uma perspectiva longitudinal em sua relação com o atributo da educação. Nesse sentido, duas questões teóricas se colocam: "Qual o impacto da experiência democrática sobre a legitimidade?" e "Quais os efeitos dos recursos individuais, especialmente do capital escolar, sobre o apoio a democracia?"

Sobre a primeira questão, as principais abordagens explicativas são as teorias da socialização e do desempenho democrático (CLAASSEN, 2020). Os estudos do primeiro grupo defendem que a relação dos cidadãos com a política pode ser interpretada como processo de aprendizado, de modo que os hábitos políticos são formados pelas várias agências de socialização, como família, escola e comunidade, bem como por eventos marcantes, experimentados, sobretudo, nos chamados anos formativos (ou impressionáveis) momento em que haveria uma espécie de tabula rasa de cultura política -, nos quais o que é vivenciado tem impacto perene na constituição do ethos político individual (DENEMARK; MATTES; NIEMI, 2016).

Nesse sentido, se indivíduos nascem, crescem e são socializados em ambientes democráticos, aprenderão a apoiar a democracia, o mesmo valendo para outros tipos de regime político (CLAASSEN, 2020, p. 34). Em termos longitudinais, a convivência democrática produziria um "legado" (CASALECCHI, 2016) e a expectativa é de que o apoio aumente à medida que novas gerações são socializadas sob regras democráticas (DENEMARK; MATTES; NIEMI, 2016).

Nesse sentido, uma primeira questão que se coloca em nossa pesquisa é quanto aos efeitos das três décadas de convivência sob regras democráticas sobre a adesão dos brasileiros à democracia. Seguindo a perspectiva teórica anteriormente esboçada, seria esperado que, à medida que a experiência democrática é acumulada, seja constituído um legado democrático, de modo que nossa primeira hipótese é que, quanto mais nos afastarmos de 1988, maior será a adesão à democracia entre os brasileiros.

A teoria do desempenho democrático é uma abordagem concorrente à teoria do aprendizado. Seu ponto de partido analítico é a perspectiva racionalista sobre a formação das atitudes e do comportamento político. Nesse sentido, o apoio à democracia seria produto da capacidade de o regime produzir resultados, de modo que os cidadãos fazem constantemente julgamentos sobre as autoridades e instituições a partir de seu funcionamento efetivo. Se as instituições funcionarem a contento, terão o apoio dos cidadãos; caso contrário, serão rejeitadas.

Existe uma divisão nessa abordagem quanto à natureza do apoio e da avaliação que os eleitores fazem do desempenho dos atores e das instituições: se é intrínseco ou instrumental (CLAASSEN, 2020). Para aqueles que definem o apoio como intrínseco, o suporte ao regime depende de sua capacidade de produzir "bens democráticos", como liberdade e accountability. Já os defensores da concepção instrumental defendem que a legitimidade é produto da capacidade de as instituições produzirem resultados tangíveis, como crescimento econômico, eficiência administrativa, segurança pública, entre outros (DALTON, 2007).

Tomando como base a teoria do desempenho democrático, espera-se, então, que o apoio à democracia se amplie à medida que, ao longo do tempo, 1) ela consiga produzir desempenho econômico satisfatório; ou 2) bens democráticos. Caso contrário, esse apoio declinará. Essa será nossa segunda hipótese para o caso brasileiro.

Os mais ambiciosos trabalhos recentes sobre o assunto têm sido desenvolvidos por Christopher Claassen (2020) ao utilizar o conceito de "mood", inicialmente empregado no campo dos estudos "macro" de opinião pública, para analisar fenômenos como avaliação de governo (DALTON, 2007). Esse enquadramento teórico concebe a dinâmica da opinião pública operando por um "modelo termostático": "quando os gastos do governo aumentam, os cidadãos preferem que diminuam; onde a política muda para a direita, as preferências dos cidadãos se movem para a esquerda" (CLAASSEN, 2020, p. 36). Aplicando o modelo ao estudo da 
legitimidade democrática, o autor propõe que "o público clamaria pela democracia quando essa fosse escassa, mas a sua preferência pela democracia enfraqueceria à medida que os direitos e as instituições democráticos fossem supridos" (CLAASSEN, 2020, p. 36, tradução nossa).

Nesse sentido, a legitimidade deve ser vista como produto da reação do público às mudanças nas instituições. Para testar seu argumento, Claasen usou três índices do projeto Varietes of Democracy (V-DEM): o Electoral Democracy Index, o Liberal Component Index, e o Liberal Democracy Index. Enquanto o primeiro mensura os elementos propriamente poliárquicos de um país, o segundo está relacionado a suas características "contramajoritárias", no sentido da capacidade de proteger direitos de minorias. Já o terceiro é a conjunção dos dois primeiros.

Conforme adiantamos, as hipóteses de Claasen eram de que avanços democráticos verificados nos países (mensurados pelos respectivos índices) causassem diminuição do apoio à democracia. Os resultados indicaram que o "humor democrático" é, sim, influenciado pelo avanço da democracia, mas somente em seu aspecto contramajoritário. Nas palavras do autor, "não são as melhorias nas instituições e processos majoritários que prejudicam o clima democrático, mas, em vez disso, o aumento da supervisão legislativa e judicial, bem como a proteção reforçada dos direitos individuais e das minorias que provocam a reação adversa" (CLAASSEN, 2020, p. 63, tradução nossa).

Considerando os resultados de Claassen sobre o humor democrático, nossa terceira hipótese, então, é que avanços institucionais na democracia brasileira pós-1988 tenham exercido um efeito negativo sobre a legitimidade democrática no país.

Os elementos destacados até aqui abordam dimensões do contexto e seus possíveis efeitos sobre a legitimidade democrática quando analisada numa perspectiva longitudinal. Contudo, como essas dimensões se articulam com aspectos individuais, entre os quais os atributos sócio-demográficos - como a educação, que é considerada o "solvente universal" das atitudes e do comportamento político (CONVERSE, 1972)?

Em primeiro lugar, deve-se reconhecer que os efeitos da escolaridade sobre a adesão a princípios e valores democráticos têm sido confirmados pela literatura (BOOTH; SELIGSON, 2009; NORRIS, 1999). Todavia, quando se analisa o sentido de tal relação numa perspectiva longitudinal, duas respostas antagônicas podem ser dadas, pois os mecanismos explicativos ainda não foram devidamente esclarecidos (SUNSHINE HILLYGUS, 2005).

A expectativa de parte da literatura é que, à medida que uma democracia se reproduz ao longo do tempo, as normas democráticas se disseminam entre os eleitores, dando origem a uma habituação (RUSTOW, 1970). Dessa forma, os efeitos de variáveis ligadas à posição dos indivíduos na estrutura social sobre o apoio à democracia seriam decrescentes. Na mesma direção, estudos empíricos indicam que os cidadãos aprendem a valorizar a democracia por meio de sua prática, de modo que anos ininterruptos de convivência democrática diminuiriam os efeitos das desigualdades de acesso à informação e à educação.

Estudo empírico de Schlegel (2010) apresentou evidências de efeitos decrescentes da educação sobre algumas atitudes e alguns comportamentos políticos. Apesar de relevante para aumentar a probabilidade de manifestação de atitudes democráticas, o autor identificou quem ao longo do tempo, esse efeito positivo vai decrescendo. A série histórica empregada nas análises, todavia, limita-se a quatro surveys, compreendidos entre 1989 e 2006, o que acreditamos ser pouco para atestar a existência de tendências consistentes, não apenas flutuações.

Outras perspectivas, porém, indicam que a educação é um recurso escasso e desigualmente distribuído (VERBA; SCHLOZMAN; BRADY, 1995) e, por diferentes motivos, seus efeitos sobre o apoio à democracia são persistentes no tempo (DELLI CARPINI; KEETER, 1997). Ainda nesse mesmo sentido, estudos comparativos analisaram os efeitos da educação sobre as atitudes políticas à medida que se amplia 0 
legado democrático de um país (FUKS; CASALECCHI; ARAÚJO, 2017; RIBEIRO; BORBA; FUKS, 2019). Os resultados indicam que contextos com maior legado democrático (combinação de durabilidade e qualidade da democracia) tendem a ampliar os efeitos da escolaridade sobre o apoio à democracia. O mecanismo explicativo para tanto seria que, mesmo que se reconheça um processo de "decantação democrática" que tenda a tornar mais competentes politicamente os indivíduos de sociedades com maior legado democrático, esse mesmo legado, porém, ao ampliar a inclusividade e a contestação no âmbito do sistema político (DAHL, 2005) traria consigo novas exigências ao cidadão no que se refere ao aspecto da internalização das normas democráticas (RIBEIRO; BORBA; FUKS, 2019, p. 34-35).

Em alusão a tais estudos e, ao ampliar o desenho longitudinal feito por Schlegel (SCHLEGEL, 2010), nossa quarta hipótese é de que os efeitos da educação sobre a adesão à democracia são crescentes à medida que se avança no tempo, em função dos crescentes desafios informacionais e cognitivos colocados pelo avanço da democracia.

\section{Trajetória Democrática e Políticas Educacionais no Brasil}

Antes de passarmos à apresentação dos aspectos metodológicos e dos resultados dos testes de hipóteses, julgamos pertinente introduzir alguns elementos contextuais importantes para a compreensão da evolução das relações entre educação e valores democráticos em nosso país. Esses elementos dizem respeito à trajetória da institucionalidade democrática nacional e das políticas educacionais que geraram uma expansão considerável em termos de cobertura desses serviços sobre a população brasileira. Seria, todavia, inviável reconstruir essas trajetórias voltando às suas raízes coloniais, que, apesar de relevantes, não cabem nos limites de um trabalho que opta por um recorte temporal iniciado pela promulgação da Constituição de 1988. Sendo assim, nos limitamos, nesta seção, ao período que vai da abertura democrática até a década inicial do século.

Comecemos pela institucionalidade política e sua relação com a estrutura social. Desde a segunda metade do século XX, o Brasil é um país urbano e industrial. A partir de 1964, foi instituída uma ditadura militar, na qual os padrões históricos de exclusão social continuaram vigentes em conjunção com o autoritarismo político (SANTOS, 1993).

A partir da Constituição Federal (CF) de 1988, houve restabelecimento da institucionalidade democrática no país. Durante o processo constituinte, ocorreu o que Arretche (2018) denomina inclusão de outsiders - quando, por exemplo, o acesso a direitos sociais como saúde e educação foram universalizados. Desde então, os fenômenos da desigualdade social e da pobreza têm sido enfrentadas de maneira mais efetiva em termos de políticas estatais. Desde a democratização, "os estratos inferiores de renda obtiveram proporcionalmente mais que os estratos superiores” (ARRETCHE, 2018, p. 401) e isto se deve, na interpretação da autora, tanto a fatores externos (boom das commodities, por exemplo) quanto ao desenho de políticas de transferência de renda.

O processo de inclusão de outsiders, iniciado na Constituição de 1988, adquiriu maior centralidade nos governos do Partidos dos Trabalhadores (2002 a 2016), especialmente pelas políticas de combate à pobreza. O resultante político desse processo promoveu um realinhamento do eleitorado, o que permitiu três reeleições seguidas por parte dos candidatos desse partido.

Em 2013, porém, tem início uma conjuntura de crises política e econômica, que perduram até o presente momento. Tais crises se iniciaram com os difusos protestos de junho de 2013, que levaram milhões de brasileiros às ruas em torno de bandeiras como "combate à corrupção" e "melhoria nos serviços públicos" (SINGER, 2018).

A partir do final de 2014 e do início de 2015, somam-se a esse cenário um grande escândalo de corrupção no âmbito da Operação Lava Jato, que atingiu parte considerável das elites econômica e política do país, especialmente o Partido dos Trabalhadores (FERES JÚNIOR; KERCHE, 2018). Acresce-se a isso, também, 
que a maior recessão da história econômica do país tem início em 2015 (BARBOSA FILHO, 2017), ocasionando o desemprego de mais de $13 \%$ da população e ampliando as desigualdades e a insegurança social. Nos dois anos seguintes, "a pobreza seguiu se ampliando, com as desigualdades de renda e regionais ampliando seu quadro já bastante deteriorado com a recessão de 2015/2016” (MELLO; WELLE; OLIVEIRA, 2018, p. 1).

Entre 2016 e 2018, a conjunção entre crise econômica e política tem continuidade. Em 2016, acontece o impeachment da presidenta Dilma Rousseff, que é substituída por seu vice, Michel Temer (LIMONGI, 2015). Os escândalos de corrupção continuam em evidência, com a continuidade da operação Lava Jato (SINGER, 2018), e a economia continua num quadro recessivo (MELLO, WELLE; OLIVEIRA, 2018). O desfecho da crise culmina com a eleição de Jair Bolsonaro, um político de extrema direita, portador de um discurso populista e autoritário, nas eleições presidenciais de 2018.

Tratando agora, especificamente, das políticas de educação, a já citada pesquisa de Schlegel (2010) aponta três legados principais da história do sistema educacional brasileiro para os dias de hoje: pouca quantidade, baixa qualidade e grande desigualdade. (SCHLEGEL, 2010, p. 95) Reunidos esses aspectos, essa herança explica nossa posição relativa desfavorável em diferentes comparações internacionais e também é fundamental para entender a natureza das relações entre escolaridade e diferentes atitudes e comportamentos políticos.

Considerando o recorte temporal definido para nossa pesquisa, a década de 1980 é caracterizada como momento de expansão da oferta dessa política, com forte pressão social para a ampliação no número de matrículas. Mesmo com esse movimento, é importante destacar que a escolarização média do brasileiro continua comparativamente baixa (VELOSO; ARAÚJO, 2009, SCHLEGEL, 2010). Helene (2012) mostra, inclusive, uma tendência de redução da taxa de crescimento da conclusão de todos os níveis (Fundamental, Médio e Superior) na década de 2000.

Sampaio e Oliveira (2015) indicam que esse acesso, além de deficitário, é marcado por profundas desigualdades entre os quartis superiores e inferiores de renda per capita, com destaque para a maior diferença no atendimento das crianças entre 0 e 3 anos de idade. No polo oposto, a desigualdade também é alarmante, já que dados de 2013 indicavam que apenas 5,1\% dos jovens entre 18 e 24 anos da camada mais pobre frequentavam o Ensino Superior, contra os 39\% registrados entre os mais ricos (SAMPAIO; OLIVEIRA, 2015, p. 515).

Conectando quantidade à qualidade, Oliveira e Araujo (2005) apontam que a expansão das matrículas ressaltou problemas internos do sistema educacional, que impediam o prosseguimento dos estudos de camadas populacionais tardiamente inseridas. Como tentativas de respostas políticas de regularização de fluxo foram implementadas, como adoção de ciclos, promoção automática e programas de aceleração. Os efeitos dessas medidas sobre indicadores de qualidade, infelizmente, foram reduzidos e o Brasil continuou a obter colocações pouco favoráveis em diferentes indicadores, como o Programa Internacional de Avaliação de Estudantes (Pisa) (INEP, 2001). Usando dados do Sistema de Avaliação do Ensino Básico (Saeb), Schlegel (2010) identifica queda em indicadores de aprendizado em língua portuguesa e matemática (as mesmas matérias avaliadas no Pisa) nos $5^{\circ}$ e $9^{\circ}$ anos do Ensino Fundamental e no $3^{\circ}$ ano do Ensino Médio na comparação entre 1995 e 2007.

A baixa qualidade interage com a desigualdade de forma perversa, pois as interrupções de fluxo escolar e os piores desempenhos tendem a se concentrar nos estratos de menor renda (SAMPAIO; OLIVEIRA, 2015). As clivagens regionais também são marcantes nessa dimensão qualitativa, com clara vantagem para as regiões Sudeste e Sul em todos os níveis educacionais (SCHLEGEL, 2010).

É preciso ter esse quadro sumário da educação nacional em mente para a interpretação dos resultados que apresentaremos mais à frente, pois os efeitos positivos das medidas de escolarização formal utilizadas sobre as atitudes democráticas dos brasileiros devem ser avaliados levando em consideração, principalmente, essa marcante desigualdade. 


\section{Metodologia}

O material empírico empregado nos testes das hipóteses apresentadas na seção anterior é resultado de um esforço de sistematização de um conjunto de fontes primárias realizado pela equipe do projeto Mudanças e Permanências nos Padrões de Participação Política no Brasil (1988-2013)4. O banco de dados reúne uma série histórica longa o suficiente (de 1989 a 2018) para avaliarmos longitudinalmente a relação dos brasileiros com a democracia considerando algumas dimensões relevantes.

Três foram as medidas selecionadas como proxys da adesão normativa e avaliativa do regime. Sobre a primeira, utilizamos medida dicotômica com as seguintes alternativas: "A democracia é o melhor regime existente", codificada como 1; e "Um regime autoritário pode ser melhor/tanto faz uma democracia ou um regime autoritário", representada por $0^{5}$. A segunda variável sobre esse primeiro aspecto da adesão diz respeito à atitude dos brasileiros em relação a uma hipotética democracia sem partidos $^{6}$. Essa medida representa, portanto, um teste da consistência da adesão, já que interroga os entrevistados sobre um aspecto específico, mas central, ao regime democrático. A codificação dessa vez define como 0 a alternativa "É possível democracia sem partidos" e como 1 "É impossível democracia sem partidos".

A dimensão avaliativa, por sua vez, é medida por uma única variável sobre a percepção dos cidadãos nacionais acerca do funcionamento da democracia no Brasil ${ }^{7}$. A escala original de quatro pontos ("nada satisfeito", "pouco satisfeito", "satisfeito" e "muito satisfeito") foi recodificada como binária pela junção das duas primeiras alternativas como 0 e das duas últimas como 1.

A análise dos dados foi conduzida em três etapas. Na primeira, verificamos descritivamente a evolução dessas três medidas e empregamos teste de sequências de Wald-Wolfowitz (MORETTIN, 1981) para identificar tendências.

Na segunda etapa, empregamos modelos logísticos multinível (SOMMET; MORSELLI, 2017) para identificar possíveis interações dos aspectos ligados aos contextos democrático e econômico nacionais com os efeitos da educação sobre as medidas de adesão à democracia. Como indicadores desse nível político nacional, utilizamos o Índice de Democracia Eleitoral e o Índice de Componente Liberal, ambos propostos pelo Varieties of Democracy (V-Dem). O primeiro é uma escala que mede a existência de processos eleitorais regulares e idôneos, enquanto o segundo mensura a existência de garantias de direitos a minorias, constituindo, assim, uma proxy da dimensão contramajoritária do regime. Para representar o contexto econômico, optamos pela taxa de desemprego, uma vez que entendemos ser essa a medida que, de maneira mais imediata, pode afetar a percepção dos brasileiros sobre a dimensão avaliativa dos resultados da democracia na perspectiva racionalista.

Por fim, em uma terceira etapa, utilizamos modelos multivariados de regressão logística (OSBORNE, 2008) para avaliarmos longitudinalmente os efeitos da educação sobre as variáveis acerca da democracia. Como controle desses efeitos, inserimos um conjunto reduzido de variáveis disponíveis ao longo da série de dados: sexo, faixa etária e avaliação da economia. Além da identificação e da discussão de movimentos de elevação e redução desses efeitos ao longo do tempo, também conduzimos aqui testes de sequência para identificar tendências gerais.

É importante alertar que existem algumas lacunas na série histórica, não coincidentes nas três variáveis. O quadro mais grave é o da medida sobre democracia sem partidos, tornando inclusive inviável a condução da segunda etapa analítica. 


\section{Tendências Longitudinais}

A primeira medida de adesão começa dividindo a amostra ao meio no início da série histórica - contexto da promulgação da nova Constituição - e, logo na sequência, apresenta salto de mais de dez pontos percentuais, o que pode representar expectativa positiva com o regime inaugurado. Todavia, em 1993, inicia-se trajetória de queda, permeada por momentos de recuperação que não chegam a atingir o patamar inicial de 50\% até 2005. Entre 2006 e 2018, experimentamos movimento de elevação no percentual de adesão, ainda que com quedas momentâneas, como entre 2011 e 2013 e, especialmente, em 2016, quando o menor nível é atingido. Por outro lado, no ano seguinte, ocorre inversão abrupta, com a adesão atingindo o recorde histórico de 77\% (Tabela 1; Fig, 1). O teste de tendência (Tabela 2), todavia, não corrobora hipóteses de crescimento ou redução em razão das oscilações, principalmente na primeira década desse século. A elevação mencionada em 2018 ainda não foi suficiente para afirmarmos uma clara tendência estatística de alta.

Tabela 1. Descritivas de variáveis sobre democracia (Brasil, 1989-2018)

\begin{tabular}{|c|c|c|c|}
\hline Ano & Adesão $(\%)^{1}$ & Democracia sem Partido (\%) ${ }^{2}$ & Satisfação $(\%)^{3}$ \\
\hline 1989 & 50,45 & - & - \\
\hline 1990 & 60,78 & 39,15 & - \\
\hline 1993 & - & 40,65 & 30,81 \\
\hline 1995 & 48 & 52,93 & 31,24 \\
\hline 1996 & 52,52 & - & 21,67 \\
\hline 1997 & 55,93 & 56,98 & 24,47 \\
\hline 1998 & 49,89 & - & 25,87 \\
\hline 2000 & 42,89 & 57,44 & 19,33 \\
\hline 2001 & 38,23 & 50,91 & 24,02 \\
\hline 2002 & 47,42 & 59,02 & 23,82 \\
\hline 2003 & 38,86 & - & 29,29 \\
\hline 2004 & 48,43 & - & 29,99 \\
\hline 2005 & 46,65 & 49,46 & 23,35 \\
\hline 2006 & 54,41 & 53,07 & 38,40 \\
\hline 2007 & 50,48 & - & 32,18 \\
\hline 2008 & 53,15 & 52,83 & 39,69 \\
\hline 2009 & 61,28 & 55,19 & 50,44 \\
\hline 2010 & 60,92 & 53,33 & 52,05 \\
\hline 2011 & 51,82 & 51,14 & 38,74 \\
\hline 2013 & 54,73 & 59,37 & 27,31 \\
\hline 2015 & 62,27 & - & 22,45 \\
\hline 2016 & 37,14 & - & 10 \\
\hline 2018 & 77,0 & 57,06 & 12,62 \\
\hline
\end{tabular}

Fonte: CESOP-Datafolha para os anos de 1989, 1990 e 1993; Latinobarômetro para os demais.

${ }^{1}$ Porcentagem de pessoas que manifestam adesão à democracia; ${ }^{2}$ Porcentagem de pessoas que discordam com uma forma de democracia sem partidos; ${ }^{3}$ Porcentagem de pessoas satisfeitas com o funcionamento da democracia no país.

A segunda medida, relativa à aceitação de uma democracia sem partidos, apresenta trajetória mais estável, após um período de crescimento inicial expressivo (Tabela 1; Fig. 1). O teste de tendência, em razão das quedas e recuperações constantes, também indica impossibilidade de rejeição da hipótese nula da aleatoriedade (Tabela 2). 
A medida de satisfação é a que mais claramente demonstra tendência, infelizmente, de redução $(-2,4019$, com p-value de 0,016) (Tabela 2). Começa no ano de 1993, com 30\% de satisfeitos, cai dez pontos logo em seguida e vai se recuperando com oscilações, até que, entre 2006 e 2010, manifesta recuperação expressiva, atingindo a marca histórica de 52\% de satisfeitos em 2010. No ano seguinte, inicia-se trajetória consistente de queda, que não se reverteu até 2018 (Tabela 1; Fig. 2).

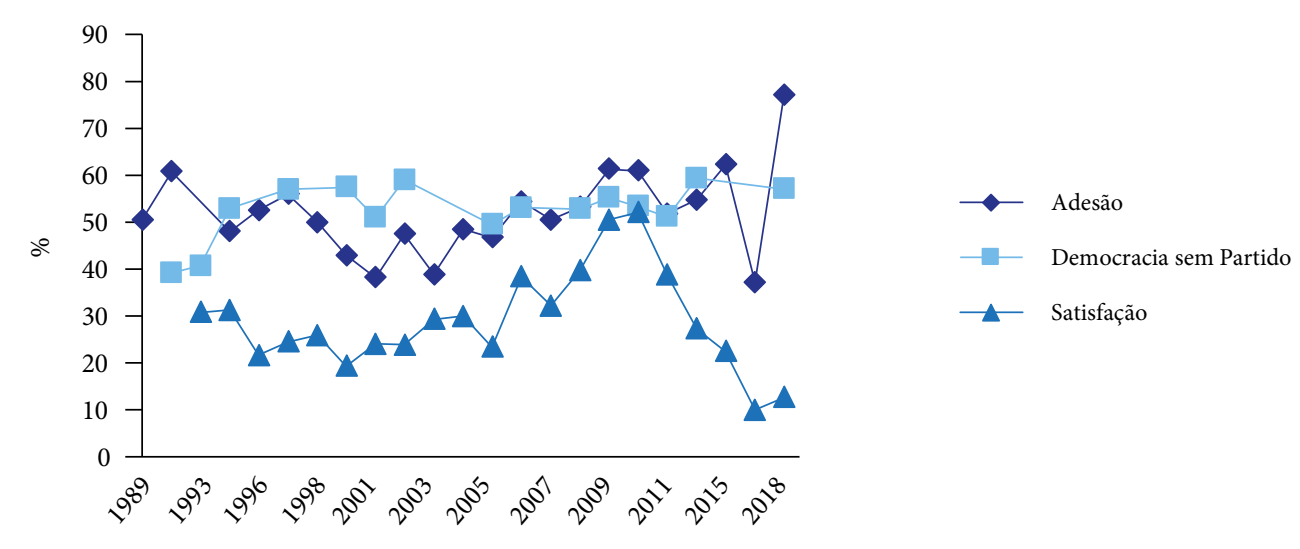

Fonte: CESOP-Datafolha para os anos de 1989, 1990 e 1993; Latinobarômetro para os demais.

As linhas representam os percentuais de adesão à democracia, de rejeição a uma democracia sem partidos e de satisfação com a democracia.

Figura 1. Evolução de indicadores sobre democracia (Brasil, 1989-2018).

Tabela 2. Testes de tendência para os indicadores sobre democracia.

\begin{tabular}{cccc} 
& Adesão & Democracia sem partidos & Satisfação \\
\hline Valor & $-0,385$ & $-1,201$ & $-2,4019$ \\
\hline Rodadas & 14 & 13 & 13 \\
\hline $\mathrm{N}$ & 28 & 26 & 26 \\
\hline sig. & 0,7001 & 0,2298 & 0,0163 \\
\hline
\end{tabular}

Fonte: CESOP-Datafolha para os anos de 1989, 1990 e 1993; Latinobarômetro para os demais.

Nota: Para o teste de tendência os dados faltantes forem preenchidos com a função na.locf do pacote zoo.

Os dados supracitados nos fornecem elementos para o teste de nossa primeira hipótese, que foi refutada pois as tendências longitudinais para as variáveis "adesão" e "democracia sem partidos" não apresentaram efeitos estatisticamente significativos. A dimensão "satisfação com a democracia", ao contrário, teve efeitos significativos, porém no sentido oposto ao esperado: ou seja, os eleitores se tornaram mais insatisfeitos com o regime à medida que nos afastamos de 1988.

Cabe aqui uma discussão sobre a mudança abrupta na dimensão da "adesão ao regime" verificada nos anos de 2016 e 2018, quando são constatados os valores mais baixos e mais altos, respectivamente. Não temos uma resposta para esses valores surpreendentes, mas é possível destacar aspectos dessa conjuntura, como as crises econômica e política pós-2014 (SINGER, 2018), o escândalo de corrupção e a Operação Lava Jato (FERES JÚNIOR; KERCHE, 2018), o impeachment (LIMONGI, 2015) e a crise de segurança pública (HUNTER; POWER, 2019). Nesse cenário, ocorreram as eleições presidenciais de 2018 (DUQUE; SMITH, 2019), quando o candidato de extrema direita Jair Bolsonaro (na época filiado ao Partido Social Liberal [PSL]) saiu vitorioso.

É nessa conjuntura que encontramos o surpreendente recorde de apoio à democracia (Tabela 1; Fig. 1), no mesmo momento em que um candidato que flertava abertamente com o autoritarismo conquistou o mais 
alto posto político da República. Uma possível interpretação dessa aparente contradição passa pelo conceito de realinhamento político, como desenvolvido por Russell Dalton (2018). Para esse autor, estaria ocorrendo, no âmbito das democracias, um processo de reorganização dos vínculos entre eleitores e partidos, a partir de duas clivagens centrais: econômicas e culturais. A globalização e a reestruturação do capitalismo, a profunda crise econômica global pós-2008, a diminuição da importância da classe trabalhadora na dinâmica do capitalismo e o surgimento de uma nova classe média são fenômenos que têm provocado mudanças profundas nas demandas da sociedade (eleitorado), ocasionando a reestruturação dos partidos e dos sistemas partidários (o lado da oferta) nas democracias avançadas, cujas consequências mais substantivas estariam sendo vistas agora.

Os fenômenos mais visíveis e emblemáticos desse processo seriam o surgimento e a consolidação dos partidos de extrema direita, por um lado, e dos partidos verdes, por outro. Nesse sentido, o aumento da adesão dos brasileiros à democracia em 2018 pode ser interpretado como resultante de um processo de realinhamento entre eleitores e partidos, de modo que um candidato de extrema direita teria propiciado uma oferta partidária congruente com as demandas da sociedade brasileira naquele momento histórico (segurança, combate à corrupção, "nova política"), traduzindo-se, dessa maneira, na ampliação do apoio ao regime.

\section{Economia, Contexto Político e Efeitos da Educação}

Para o teste das hipóteses dois e três, buscamos verificar como os contextos político e econômico nacionais se relacionam às dimensões da adesão e da satisfação com a democracia, em perspectiva longitudinal. Entramos aqui numa dimensão mais explicativa em relação às tendências encontradas na seção anterior.

Por meio de modelos multinível, procuramos identificar, principalmente, se indicadores desses contextos moderam os efeitos da escolaridade individual sobre as atitudes democráticas selecionadas. Como alertamos na seção metodológica, a medida sobre democracia sem partidos foi excluída desta etapa. Com essa exclusão, também foi possível inserir um controle adicional aos modelos: a avaliação da economia nacional. As duas outras medidas de atitudes democráticas são incluídas como variáveis dependentes em modelos que consideram cada um dos anos uma unidade de nível macro, sendo os dados individuais tomados como nível micro.

A Tabela 3 apresenta os resultados desse procedimento para a medida de adesão, com os exponenciais das razões de chance dos preditores individuais na primeira coluna (Mod.1). Os resultados confirmam o efeito positivo da educação sobre essa atitude política. A segunda coluna (Mod.2) mostra resultados de modelo com a adição dos preditores de nível macro e indica efeitos significativos e negativos para a medida de democracia eleitoral e para a taxa de desemprego. Já a medida do Índice de Componente Liberal não apresentou efeitos significativos. Dessa maneira, coerentemente com as hipóteses dois e três (ambas em caráter parcial), foi possível identificar a importância dos elementos do contexto econômico e político no apoio à democracia.

Existiria, assim, um duplo processo, que explicaria a dinâmica do apoio à democracia brasileira. Por um lado, um componente de "humor" democrático, que opera na forma de modelo termostático - quando melhorias na qualidade da democracia são seguidas por avaliações negativas dela, confirmando a hipótese três. Esse resultado, todavia, apresenta importante diferença em relação aos achados de Claassen (2020), uma vez que foi a medida de qualidade da democracia, em sua dimensão eleitoral, não a contra-majoritária, que se mostrou relevante. Isso sugere, portanto, que, no caso de jovens democracias, como a brasileira, o elemento mais importante no "termostato democrático" ainda é esse nível mais básico de institucionalização.

Por outro lado, o apoio também é produto do desempenho econômico, no nosso caso mensurado pela taxa de desemprego. É como se economia e política impactassem de modos opostos a maneira como os eleitores definem suas atitudes democráticas. 
De modo a complementar nossos resultados e subsidiar a discussão sobre a hipótese quatro, a ser realizada na seção seguinte, interagimos o Índice de Democracia Eleitoral com a medida educacional e constatamos um efeito positivo estatisticamente significativo na categoria de alta escolaridade (Mod.3). O mesmo exercício foi conduzido usando a taxa de desemprego (Mod.4), encontrando resultado semelhante, porém ligeiramente maior.

Tabela 3. Condicionantes individuais e nacionais da adesão à democracia (Brasil, 1989-2018).

\begin{tabular}{|c|c|c|c|c|}
\hline Variáveis & Mod.1 & Mod.2 & Mod.3 & Mod.4 \\
\hline Sexo (Homem) & $1,20^{\star * \star}(0,03)$ & $1,20^{\star * \star}(0,03)$ & $1,20^{\star \star \star}(0,03)$ & $1,20^{\star \star \star}(0,03)$ \\
\hline \multicolumn{5}{|l|}{ Faixa Etária } \\
\hline $16-25$ & Ref. & Ref. & Ref. & Ref. \\
\hline $26-40$ & $1,13^{* * *}(0,04)$ & $1,13^{* * *}(0,04)$ & $1,13^{\star * *}(0,04)$ & $1,13^{\star * \star}(0,04)$ \\
\hline $41+$ & $1,49^{\star * *}(0,04)$ & $1,49^{* * *}(0,04)$ & $1,49^{* * *}(0,04)$ & $1,48^{\star * \star}(0,04)$ \\
\hline \multicolumn{5}{|l|}{ Educação } \\
\hline Baixa & Ref. & Ref. & Ref. & Ref. \\
\hline Média & $1,37^{\star * *}(0,03)$ & $1,37^{\star * *}(0,03)$ & $0,83(0,58)$ & $1,14(0,14)$ \\
\hline Alta & $2,37^{\star * *}(0,05)$ & $2,37^{\star * *}(0,05)$ & $0,13^{\star}(0,92)$ & $1,34(0,20)$ \\
\hline \multicolumn{5}{|l|}{ Avaliação da Economia } \\
\hline Negativa & Ref. & Ref. & Ref. & Ref. \\
\hline Neutra & $1,19^{\star * \star}(0,03)$ & $1,19^{\star * \star}(0,04)$ & $1,19^{\star * \star}(0,03)$ & $1,19^{\star \star \star}(0,03)$ \\
\hline Positiva & $1,34^{\star * \star}(0,04)$ & $1,35^{\star \star \star}(0,04)$ & $1,35^{\star \star \star}(0,04)$ & $1,35^{\star * *}(0,04)$ \\
\hline Índice de Democracia Eleitoral & - & $0,89^{\star * *}(0,01)$ & $0,89^{\star * \star}(0,01)$ & $0,89(0,01)$ \\
\hline Índice de Componente Liberal & & $0,99(0,01)$ & $0,99(0,01)$ & $0,99(0,01)$ \\
\hline Desemprego & - & $0,91^{\star * \star}(0,02)$ & $0,91^{\star * \star}(0,02)$ & $0,90^{* * *}(0,02)$ \\
\hline $\begin{array}{l}\text { Educação Média* Índice de } \\
\text { Democracia Eleitoral }\end{array}$ & - & - & $1,01(0,01)$ & - \\
\hline $\begin{array}{l}\text { Educação Alta* Índice de } \\
\text { Democracia Eleitoral }\end{array}$ & - & - & $1,03^{* *}(0,01)$ & - \\
\hline Educação Média* Desemprego & - & - & - & $1,02(0,01)$ \\
\hline Educação Alta* Desemprego & - & - & - & $1,06^{* *}(0,02)$ \\
\hline $\mathrm{N}$ ano & 20 & 20 & 20 & 20 \\
\hline $\mathrm{N}$ & 22496 & 22496 & 22496 & 22496 \\
\hline $\mathrm{AIC} / \mathrm{BIC}$ & $28995,9 / 29068,1$ & $24318,2 / 24419,7$ & $28965,0 / 29077,3$ & $28965,6 / 29077,9$ \\
\hline $\mathrm{R} 2$ marginal/condicional & $0,034 / 0,072$ & $0,055 / 0,064$ & $0,106 / 0,113$ & $0,109 / 0,115$ \\
\hline
\end{tabular}

Fonte: CESOP-Datafolha para os anos de 1989, 1990 e 1993; Latinobarômetro para os demais.

${ }^{* * *}$ sig $<0,001 ;{ }^{* *}$ sig $<0,01 ;{ }^{*}$ sig $<0,05$

Os resultados do segundo modelo para a medida de satisfação com a democracia (Tabela 4) confirmam a relevância da medida de democracia eleitoral, inclusive indicando maior impacto do que o registrado nos modelos para a medida de adesão. O Índice de Componente Liberal não apresentou efeitos significativos para a satisfação com a democracia, assim como a taxa de desemprego. A ausência de efeito dessa última variável não deixa de ser surpreendente, pois a literatura tende a considerar a satisfação com o regime mais impactada por aspectos conjunturais do que o apoio "abstrato" ou "difuso", que dependeria mais de aspectos de longo prazo.

Dessa maneira, é possível indicar a refutação da hipótese dois para a medida de satisfação com a democracia e a confirmação parcial da hipótese três. 
Por fim, de modo a subsidiar o teste da hipótese quatro, na seção seguinte, fizemos novamente a interação crosslevel (Mod.3), entre escolaridade e Índice de Democracia Eleitoral. O modelo retornou efeitos significativos para as duas categorias educacionais, em ambos os casos indicando redução de $3 \%$ sobre a satisfação com a democracia. Nos anos em que essa medida de contexto político apresenta melhoras, portanto, as diferenças na probabilidade de satisfação entre os grupos educacionais tendem a diminuir. As interações com taxa de desemprego não retornaram efeitos significativos (Mod.4), assim como essa medida econômica quando tomada de forma independente (Mod.2).

Tabela 4. Condicionantes individuais e nacionais da satisfação com democracia (Brasil, 1989-2018).

\begin{tabular}{|c|c|c|c|c|}
\hline Variáveis & Mod.1 & Mod.2 & Mod.3 & Mod.4 \\
\hline Sexo (Homem) & $1,24^{* * *}(0,03)$ & $1,24^{* * *}(0,03)$ & $1,24^{\star * \star}(0,03)$ & $1,14^{\star * *}(0,03)$ \\
\hline \multicolumn{5}{|l|}{ Faixa Etária } \\
\hline $16-25$ & Ref. & Ref. & Ref. & Ref. \\
\hline $26-40$ & $1,05(0,04)$ & $1,05(0,04)$ & $1,04(0,04)$ & $1,05(0,04)$ \\
\hline $41+$ & $1,34^{\star * *}(0,04)$ & $1,34^{\star * *}(0,04)$ & $1,33^{\star * *}(0,04)$ & $1,34^{\star * *}(0,04)$ \\
\hline \multicolumn{5}{|l|}{ Educação } \\
\hline Baixa & Ref. & Ref. & Ref. & Ref. \\
\hline Média & $0,79^{\star * *}(0,04)$ & $0,79^{\star * *}(0,04)$ & $0,79(0,16)$ & $0,79(0,16)$ \\
\hline Alta & $0,87^{\star *}(0,05)$ & $0,86^{\star * *}(0,05)$ & $0,84(0,21)$ & $0,84(0,21)$ \\
\hline \multicolumn{5}{|l|}{ Avaliação da Economia } \\
\hline Negativa & Ref. & Ref. & Ref. & Ref. \\
\hline Neutra & $1,97^{\star * *}(0,04)$ & $1,97^{\star *}(0,04)$ & $1,97^{\star * *}(0,04)$ & $1,97^{\star * *}(0,04)$ \\
\hline Positiva & $4,93^{\star * *}(0,04)$ & $4,92^{\star * \star}(0,04)$ & $4,94^{\star * \star}(0,04)$ & $4,93^{\star * \star}(0,04)$ \\
\hline Índice de Democracia Eleitoral & - & $1,06^{\star *}(0,02)$ & $1,08^{\star \star}(0,03)$ & $1,06^{* \star}(0,02)$ \\
\hline Índice de Componente Liberal & & $1,00(0,02)$ & $1,00(0,02)$ & $1,00(0,02)$ \\
\hline Desemprego & - & $0,94(0,04)$ & $0,94(0,04)$ & $0,94(0,04)$ \\
\hline $\begin{array}{l}\text { Educação Média* Índice de } \\
\text { Componente Liberal }\end{array}$ & - & & $0,97^{\star * \star}(0,01)$ & - \\
\hline $\begin{array}{l}\text { Educação Alta* Índice de } \\
\text { Componente Liberal }\end{array}$ & & & $0,97^{\star}(0,01)$ & - \\
\hline Educação Média* Desemprego & - & - & - & $1,00(0,02)$ \\
\hline Educação Alta* Desemprego & - & - & - & $1,00(0,02)$ \\
\hline $\mathrm{N}$ ano & 20 & 20 & 20 & 20 \\
\hline $\mathrm{N}$ & 24284 & 24284 & 24284 & 24284 \\
\hline $\mathrm{AIC} / \mathrm{BIC}$ & $24996,8 / 25069,7$ & $24994,2 / 25091,4$ & $24982,5 / 25095,8$ & $24998,2 / 25111,6$ \\
\hline $\mathrm{R} 2$ marginal/condicional & $0,103 / 0,146$ & $0,159 / 0,185$ & $0,159 / 0,185$ & $0,159 / 0,185$ \\
\hline
\end{tabular}

Fonte: CESOP-Datafolha para os anos de 1989, 1990 e 1993; Latinobarômetro para os demais.

${ }^{* * *} \operatorname{sig}<0,001 ;{ }^{* *}$ sig $<0,01 ;{ }^{*}$ sig $<0,05$.

\section{Efeitos Longitudinais da Educação}

Os efeitos positivos (sobre a adesão à democracia) e negativos (sobre a avaliação da democracia) da educação, identificados na seção anterior, podem ser conhecidos em detalhes ao estimá-los ao longo do tempo. Essas estimativas, que dizem respeito à nossa quarta hipótese, são produzidas por meio de modelos logísticos de regressão para cada um dos anos, usando como controles o sexo e a faixa 
etária dos indivíduos. Como a escolaridade é codificada em três categorias, são reportados nas tabelas abaixo os exponenciais das razões de chance para os níveis médio e alto, tendo como referência a baixa escolaridade ${ }^{8}$.

Sobre a medida de adesão, a Tabela 5 apresenta resultados sugerindo a relevância da educação em toda a série histórica. É possível perceber que a diferença dos efeitos entre baixa (referência) e alta escolaridade é significativa em quase todos os anos (as exceções são 1997 e 2010), enquanto são várias as lacunas nos contrastes entre baixa e média (1995, 1997, 2002, 2004, 2007, 2010, 2011, 2013 e 2015). As distinções entre os extremos, portanto, tendem a ser mais consistentes ao longo do período, sempre com maior adesão à democracia entre os mais educados. A maior diferença registrada foi em 2000, ano em que um indivíduo com alta escolaridade apresentou probabilidade $355 \%$ maior de pertencer ao grupo dos que consideram a democracia a melhor forma de governo.

Tabela 5. Efeitos da escolaridade sobre a adesão à democracia (Brasil, 1989-2018).

\begin{tabular}{ccccccccc}
\hline \multirow{2}{*}{ Ano } & \multicolumn{4}{c}{ Educação } & \multirow{2}{*}{ Ano } & \multicolumn{3}{c}{ Educação } \\
\cline { 8 - 9 } & Baixa & Média & Alta & & Baixa & Média & Alta \\
\hline 1989 & Ref. & $1,45^{* *}(0,12)$ & $2,02^{* * *}(0,15)$ & 2005 & & Ref. & $1,55^{* *}(0,15)$ & $2,62^{* * *}(0,22)$ \\
\hline 1990 & Ref. & $1,46^{* * *}(0,11)$ & $2,07^{* * *}(0,14)$ & 2006 & & Ref. & $1,87^{* * *}(0,16)$ & $2,68^{* * *}(0,21)$ \\
\hline 1995 & Ref. & $1,35(0,18)$ & $2,19^{* * *}(0,23)$ & 2007 & & Ref. & $1,17(0,15)$ & $1,84^{* *}(0,20)$ \\
\hline 1996 & Ref. & $1,85^{* * *}(0,15)$ & $2,61^{* * *}(0,18)$ & 2008 & & Ref. & $1,84^{* * *}(0,14)$ & $3,08^{* *}(0,20)$ \\
\hline 1997 & Ref. & 1,34 & $1,97(0,51)$ & 2009 & & Ref. & $1,44^{*}(0,15)$ & $2,79^{* * *}(0,22)$ \\
\hline 1998 & Ref. & $1,42^{*}(0,15)$ & $2,84^{* * *}(0,21)$ & 2010 & & Ref. & $1,08(0,14)$ & $1,37(0,20)$ \\
\hline 2000 & Ref. & $1,71^{* * *}(0,16)$ & $4,55^{* * *}(0,20)$ & 2011 & & Ref. & $0,94(0,14)$ & $1,61^{*}(0,19)$ \\
\hline 2001 & Ref. & $1,67^{* *}(0,19)$ & $2,04^{* *}(0,24)$ & 2013 & & Ref. & $1,18(0,14)$ & $1,89^{* * *}(0,19)$ \\
\hline 2002 & Ref. & $1,35(0,18)$ & $2,46^{* * *}(0,27)$ & 2015 & & Ref. & $1,22(0,16)$ & $2,13^{* * *}(0,20)$ \\
\hline 2003 & Ref. & $1,71^{* *}(0,16)$ & $3,44^{* * *}(0,22)$ & 2016 & & Ref. & $1,37^{*}(0,16)$ & $3,68^{* * *}(0,18)$ \\
\hline 2004 & Ref. & $1,25(0,16)$ & $2,77^{* * *}(0,23)$ & 2018 & & Ref. & $1,20^{*}(0,08)$ & $1,58^{* * *}(0,13)$ \\
\hline
\end{tabular}

Fonte: CESOP-Datafolha para os anos de 1989, 1990 e 1993; Latinobarômetro para os demais.

${ }^{* * *}$ sig $<0,001 ;{ }^{* *}$ sig $<0,01 ;{ }^{*}$ sig $<0,05$.

A evolução dos efeitos desses níveis educacionais pode ser detalhada com o cálculo das probabilidades preditas mantendo estáveis os demais controles. A Fig. 2 apresenta, portanto, as probabilidades de adesão à democracia de homens com idade entre 26 e 40 anos que se diferenciam apenas no que diz respeito ao nível de escolaridade. Podemos perceber que, ao longo de todo o tempo, as posições relativas das probabilidades vão se mantendo, com vantagem para o perfil com alta escolaridade, com momentos de oscilação (ascendente e descendente) coincidentes, ainda que o perfil com alta escolaridade seja ligeiramente mais estável. Chamam a atenção, todavia, alguns momentos de aproximação, como os ocorridos entre média e baixa escolaridades a partir de 2010 e entre os três níveis em 2007 e 2018. Nesses dois últimos momentos, a adesão à democracia, que, ao longo do quase três décadas, mostrou-se fortemente impactada pela desigualdade educacional, parece se descolar dessa variável socioeconômica.

O teste de tendência para esses valores preditos indica que apenas o perfil de alta escolaridade (ainda assim com p-value de 0,10 ) apresenta tendência não aleatória de elevação (Tabela 6). 


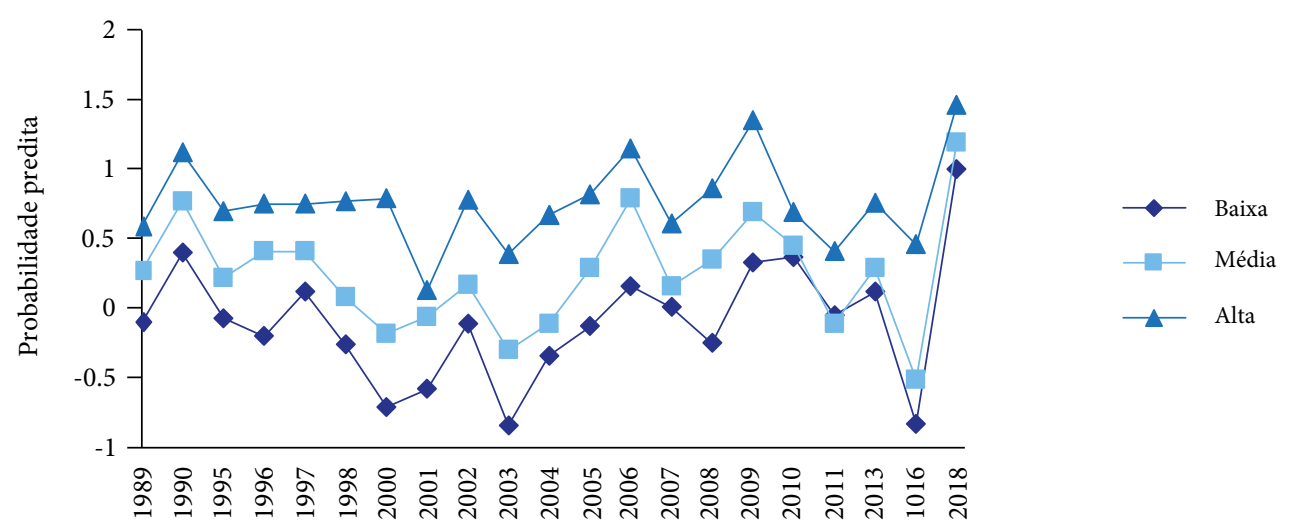

Fonte: CESOP-Datafolha para os anos de 1989, 1990 e 1993; Latinobarômetro para os demais.

Nota: Probabilidades de homens, na faixa etária de 26 a 40 anos.

Figura 2. Probabilidades preditas de adesão à democracia por nível de escolaridade (Brasil, 1989-2018).

Tabela 6. Testes de tendência para probabilidades preditas de adesão à democracia por nível de escolaridade (Brasil, 1989-2018).

\begin{tabular}{cccc} 
& Baixa & Média & Alta \\
\hline Valor & $-0,919$ & 0,000 & 1,669 \\
\hline Rodadas & 9 & 11 & 14 \\
\hline $\mathrm{N}$ & 20 & 20 & 19 \\
\hline sig. & 0,3581 & 0,9999 & 0,0949 \\
\hline
\end{tabular}

Fonte: CESOP-Datafolha para os anos de 1989, 1990 e 1993; Latinobarômetro para os demais.

Quadro bastante distinto é encontrado quando a variável dependente é a medida sobre democracia sem partidos (Tabela 7). Diferenças estatisticamente significativas entre os níveis de escolaridade foram encontradas em apenas quatro anos: 1990, 2005, 2010 e 2018 entre baixa e média escolaridades; e 1990, 2000, 2002 e 2011 entre baixa e alta escolaridades.

Tabela 7. Efeitos da escolaridade sobre a rejeição de uma democracia sem partidos (Brasil, 1989-2018).

\begin{tabular}{ccccccccc}
\hline \multirow{2}{*}{ Ano } & \multicolumn{3}{c}{ Educação } & \multirow{2}{*}{ Ano } & & \multicolumn{3}{c}{ Educação } \\
\cline { 2 - 3 } \cline { 8 - 9 } & Baixa & Média & Alta & & Baixa & Média & Alta \\
\hline 1990 & Ref. & $2,11^{* * *}(0,11)$ & $5,59^{* * *}(0,14)$ & 2006 & & Ref. & $0,77(0,16)$ & $0,77(0,20)$ \\
\hline 1995 & Ref. & $0,81(0,18)$ & $1,10(0,22)$ & 2008 & & Ref. & $0,82(0,14)$ & $0,81(0,19)$ \\
\hline 1997 & Ref. & $1,36(0,46)$ & $1,08(0,49)$ & 2009 & & Ref. & $0,79(0,15)$ & $0,71(0,19)$ \\
\hline 2000 & Ref. & $1,06(0,16)$ & $1,51^{*}(0,19)$ & 2010 & & Ref. & $0,74^{*}(0,15)$ & $0,78(0,19)$ \\
\hline 2001 & Ref. & $0,82(0,24)$ & $0,88(0,24)$ & 2011 & & Ref. & $0,90(0,14)$ & $0,66^{*}(0,19)$ \\
\hline 2002 & Ref. & $0,91(0,18)$ & $0,51^{* *}(0,26)$ & 2013 & & Ref. & $0,63^{* *}(0,15)$ & $0,70(0,19)$ \\
\hline 2005 & Ref. & $0,66^{* *}(0,15)$ & $0,85(0,22)$ & 2018 & & Ref. & $0,83^{* *}(0,07)$ & $0,91(0,10)$ \\
\hline
\end{tabular}

Fonte: CESOP-Datafolha para os anos de 1989, 1990 e 1993; Latinobarômetro para os demais.

${ }^{* * *} \operatorname{sig}<0,001 ;{ }^{* *} \operatorname{sig}<0,01 ;{ }^{*} \operatorname{sig}<0,05$.

Ainda que restrita a poucos momentos, a trajetória desses efeitos é interessante, pois eles apontam para destacada relevância no momento inicial de abertura democrática, com impressionante diferença entre alta e baixa escolaridades, de mais de $450 \%$ na probabilidade de rejeição da hipótese de uma democracia 
sem partidos. A diferença vai caindo, como em 2000, quando desce para 51\%, e se inverte em 2002. Nesse ano, um indivíduo com alta escolaridade apresentou probabilidade $49 \%$ menor de rejeição desse regime hipotético em comparação com um perfil de baixa escolaridade. Em 2011, esse quadro continua, ainda que com uma ligeira redução.

A Fig. 3, com os valores preditos das três categorias de escolaridade, ilustra a mudança radical do momento inicial (1990) para o restante da série. A partir de 2002 os mais escolarizados passam a aderir mais à ideia de uma democracia sem partidos e, com aproximações e afastamentos em comparação com a categoria média, mantêm-se abaixo da categoria dos menos escolarizados. Como indica a Tabela 8, é também apenas essa categoria de alta escolarização que demonstra clara tendência longitudinal, infelizmente de redução. Essa afirmação, todavia, é prejudicada pela recorrência de efeitos não significativos (valores próximos da linha 0 no eixo vertical).

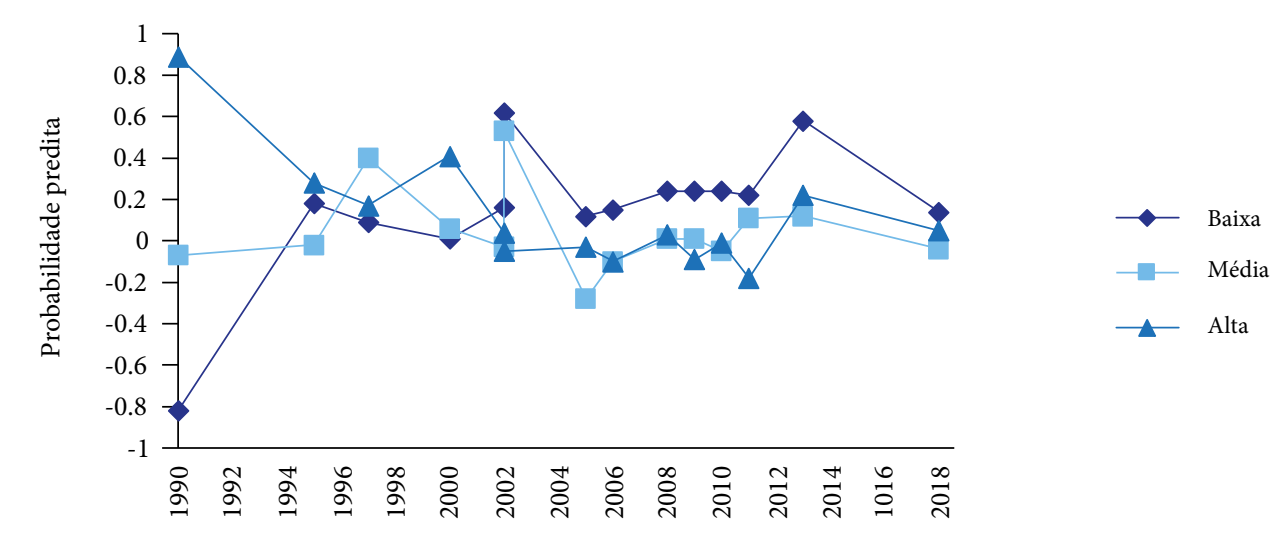

Fonte: CESOP-Datafolha para os anos de 1990; Latinobarômetro para os demais.

Nota: Probabilidades de homens, na faixa etária de 26 a 40 anos.

Figura 3. Probabilidades preditas de rejeição à uma democracia sem partidos (Brasil, 1989-2018).

Tabela 8. Testes de tendência para probabilidades preditas de rejeição a uma democracia sem partidos (Brasil, 1989-2018)

\begin{tabular}{cccc} 
& Baixa & Média & Alta \\
\hline Valor & $-0,556$ & 0,556 & $-2,782$ \\
\hline Rodadas & 7 & 9 & 3 \\
\hline $\mathrm{N}$ & 14 & 14 & 14 \\
\hline sig. & 0,5780 & 0,5780 & 0,0054 \\
\hline
\end{tabular}

Fonte: CESOP-Datafolha para os anos de 1989, 1990 e 1993; Latinobarômetro para os demais.

Sobre a medida de satisfação com a democracia, o quadro geral é parecido com o da variável anterior, pois os efeitos significativos se limitaram a alguns anos (Tabela 9). Os impactos também tendem a ser negativos. Comparadas com a categoria de referência, escolaridades média e alta reduzem a probabilidade de os entrevistados pertencerem ao grupo dos satisfeitos com o funcionamento da democracia no Brasil. A única exceção aparece em 1998, quando registramos efeito positivo de 55\%, provocado pela categoria de alta escolarização. O ápice desse efeito negativo foi registrado em 2004, quando uma pessoa altamente escolarizada apresentou chance $58 \%$ menor de satisfação. Para a categoria intermediária, o maior efeito negativo foi registrado em 2002, com probabilidade $61 \%$ menor. 
Tabela 9. Efeitos da escolaridade sobre a avaliação positiva acerca do funcionamento da democracia (Brasil, 1989-2018)

\begin{tabular}{cccccccc}
\hline \multirow{2}{*}{ Ano } & \multicolumn{3}{c}{ Educação } & & \multirow{2}{*}{ Ano } & \multicolumn{3}{c}{ Educação } \\
\cline { 2 - 4 } \cline { 7 - 8 } & Baixa & Média & Alta & & Baixa & Média & Alta \\
\hline 1993 & $0,79^{*}(0,11)$ & $0,72^{*}(0,14)$ & 2006 & & $0,81(0,15)$ & $0,44^{* * *}(0,22)$ \\
\hline 1995 & $0,63^{*}(0,21)$ & $0,67(0,25)$ & 2007 & & $0,86(0,15)$ & $0,59^{*}(0,23)$ \\
\hline 1996 & $1,01(0,17)$ & $1,37(0,20)$ & 2008 & & $0,82(0,14)$ & $0,98(0,19)$ \\
\hline 1997 & $0,48(0,48)$ & $0,78(0,51)$ & 2009 & & $0,77(0,14)$ & $0,78(0,18)$ \\
\hline 1998 & $0,98(0,17)$ & $1,55^{*}(0,21)$ & 2010 & & $0,86(0,14)$ & $0,87(0,18)$ \\
\hline 2000 & $0,87(0,20)$ & $1,13(0,22)$ & 2011 & & $0,88(0,14)$ & $1,11(0,18)$ \\
\hline 2001 & $0,82(0,22)$ & $0,82(0,29)$ & 2013 & & $0,78(0,15)$ & $0,75(0,21)$ \\
\hline 2002 & $0,39^{* * *}(0,25)$ & $0,54(0,33)$ & 2015 & & $0,63^{* *}(0,18)$ & $0,97(0,21)$ \\
\hline 2003 & $0,87(0,17)$ & $0,65(0,24)$ & 2016 & & $0,62(0,25)$ & $0,91(0,28)$ \\
\hline 2004 & $0,71^{*}(0,17)$ & $0,42^{* *}(0,27)$ & 2018 & & $1,08(0,10)$ & $1,27(0,14)$ \\
\hline 2005 & $0,49^{* * *}(0,19)$ & $0,82(0,25)$ & & & & \\
\hline
\end{tabular}

Fonte: CESOP-Datafolha para os anos de 1989, 1990 e 1993; Latinobarômetro para os demais.

${ }^{* * *} \operatorname{sig}<0,001,{ }^{* *} \operatorname{sig}<0,01,{ }^{*} \operatorname{sig}<0,05$.

A Fig. 4, com as probabilidades preditas por perfil educacional, mostra como essa variável foi pouco expressiva na maior parte da série histórica, já que são poucos os momentos em que as linhas se separaram de modo marcante. Com fortes oscilações ao longo dos anos, nenhum dos perfis apresentou tendência clara na evolução dos seus valores preditos (Tabela 10), apesar do período de melhora, entre 2007 e 2010.

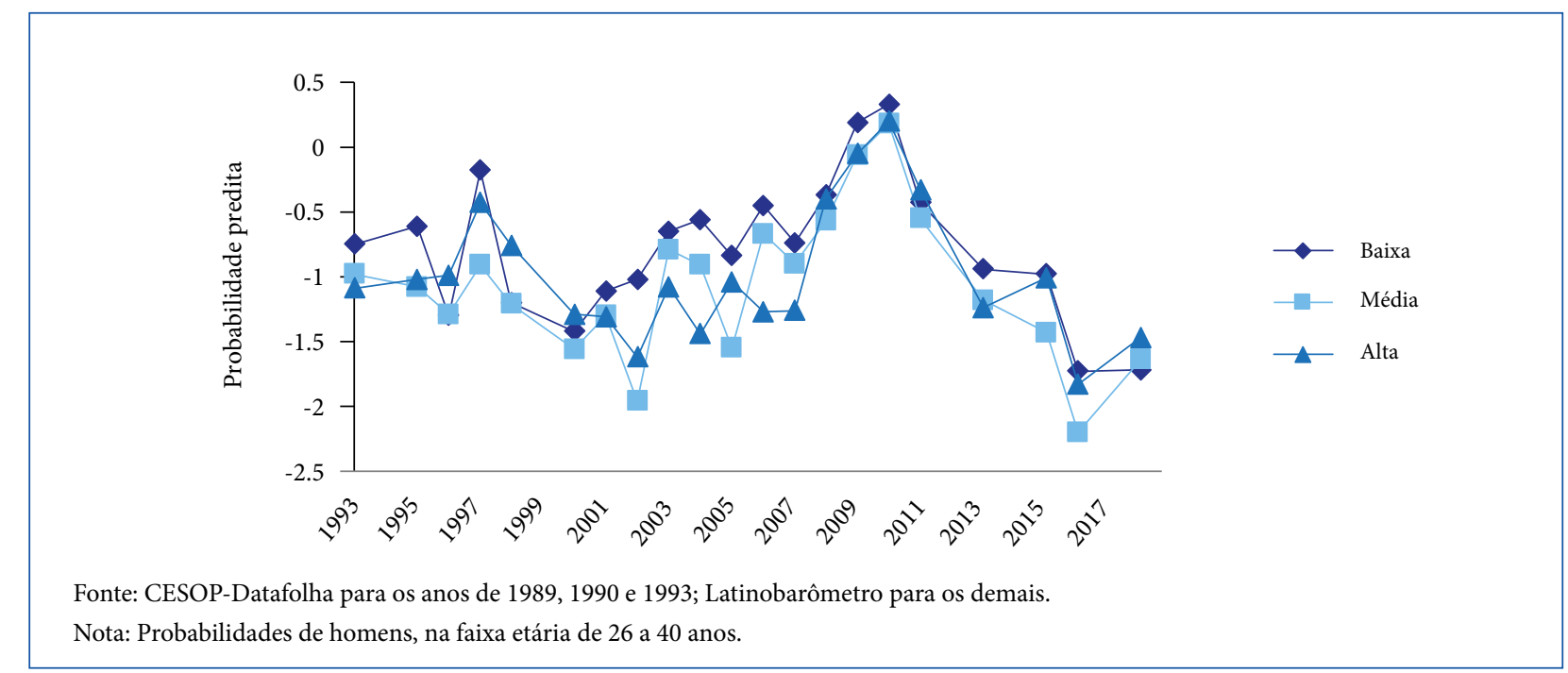

Figura 4. Probabilidades preditas de avaliação positiva do funcionamento da democracia (Brasil, 1989-2018).

Retomando aqui nossa última hipótese, a expectativa era de que o tempo de democracia ao colocar crescentes demandas informacionais e cognitivas aos eleitores, ampliasse a relevância da clivagem educacional sobre as atitudes pró-democracia. No que diz respeito à medida de adesão, essa expectativa foi plenamente confirmada, com efeito recorrente, positivo e expressivo da educação superior ao longo de toda a série histórica. As probabilidades de adesão para cidadãos com esse nível educacional são sempre maiores, ainda que, em alguns momentos, como no final do período, essa diferença diminua. Essa conclusão é a mesma 
observada nos modelos multinível da seção anterior, nos quais foram identificados efeitos expressivos dessa condição educacional, inclusive crescentes em momentos de melhoria do indicador de qualidade da democracia eleitoral.

Não podemos afirmar o mesmo sobre a medida de rejeição a uma democracia sem partidos, já que os efeitos da educação são raramente verificados e, quando existem, geram reduções na medida dependente.

Tabela 10. Testes de tendência para probabilidades preditas de avaliação positiva do funcionamento da democracia (Brasil, 1989-2018)

\begin{tabular}{cccc} 
& Baixa & Média & Alta \\
\hline Valor & $-1,378$ & $-1,378$ & $-0,919$ \\
\hline Rodadas & 7 & 8 & 9 \\
\hline $\mathrm{N}$ & 20 & 20 & 20 \\
\hline sig. & 0,1681 & 0,1681 & 0,358 \\
\hline
\end{tabular}

Fonte: CESOP-Datafolha para os anos de 1989, 1990 e 1993; Latinobarômetro para os demais.

\section{Considerações Finais}

Se as primeiras avaliações, feitas na década de 1990, sobre a adesão dos brasileiros à democracia permitiam traçar um cenário otimista (MOISÉS, 1995), esse não parece ser o quadro atual. Para a maioria dos indicadores analisados, constatamos estabilidade ou reversão das expectativas iniciais. Nesse sentido, a crise iniciada em 2013-2014 parece ter sido o ponto de explosão de um conjunto crescente de sentimentos bastante negativos do eleitorado para com o funcionamento da democracia no país e suas instituições, culminando com a eleição de Jair Bolsonaro, em 2018.

Sobre a relação entre educação e atitudes democráticas, vimos tendências distintas para o conjunto das variáveis analisadas, porém a democratização parece não ter sido capaz de propiciar aprendizado democrático de modo a superar os efeitos das desigualdades de recursos (especialmente a escolarização), historicamente presentes no eleitorado brasileiro.

Os resultados do estudo reforçam a importância de uma agenda de estudos que tem crescido na Ciência Política nacional, mas que ainda carece de avanços: a qualidade da democracia (MOISÉS; MENEGUELLO, 2013). Ao que tudo indica, a formação de cidadãos mais competentes e democráticos requer mais do que o simples funcionamento ininterrupto de instituições democráticas, ainda que essas representem, de fato, um avanço do ponto de vista institucional. Seria preciso revesti-las também com qualidade - responsividade, transparência, serviço público eficiente e outras características que devem ser especificadas e aprofundadas em estudos futuros.

Os achados ainda acentuam a necessidade de estratégias que minimizem os efeitos da desigualdade no quadro educacional brasileiro, já que seus impactos parecem também ser significativos sobre dimensões atitudinais relevantes, como as analisadas aqui. Políticas públicas desenhadas para a redução das disparidades e clivagens educacionais podem ter o efeito marginal positivo de disseminar e consolidar o apoio democrático entre os brasileiros.

\section{Contribuições dos Autores}

Problematização e Conceitualização, Ribeiro EA e Borba J; Metodologia, Robeiro EA e Borba J; Análise, Ribeiro EA e Borba J; Redação, Ribeiro EA e Borba J. 


\section{Notas}

1. Easton (1967) se refere às "chamadas regras do jogo [...], os princípios constitucionais".

2. Considerando que nossos dados são oriundos de surveys populacionais, consideramos educação sinônimo de escolarização formal, para fins de operacionalização dessa variável.

3. Projeto "Mudanças e Permanências nos Padrões de Participação Política no Brasil" (UFSC, UEM, UNESP), Procad/CAPES, edital 2013.

4. O projeto envolve pesquisadores e alunos de graduação e pós-graduação e conta com financiamento da CAPES, por meio do edital Procad/2013. Maiores informações em www.participacaopolitica.cfh.ufsc.br.

5. Nos bancos do CESOP-Datafolha (1989 e 1990), a questão original é "Eu gostaria que você me dissesse com qual das três frases seguintes você concorda mais: 1) A democracia é sempre melhor do que qualquer outra forma de governo; 2) Em certas circunstâncias, é melhor uma ditadura do que um regime democrático; 3) Tanto faz se o governo é uma democracia ou uma ditadura”. Nos bancos do Latinobarômetro (1995-2018), a redação é “Com qual dessas afirmações está mais de acordo? 1) A democracia é sempre preferível a qualquer outra forma de governo; 2) Em certas situações, um governo autoritário pode ser preferível a uma democracia; 3) Para pessoas como eu, tanto faz um governo democrático ou autoritário".

6. Nos bancos do CESOP-Datafolha (1990 e 1993), a questão original é "Na sua opinião, os partidos políticos? 1) São indispensáveis à democracia; 2) Só servem para defender os políticos”. Nos bancos do Latinobarômetro (1995-2018), a questão é "Algumas pessoas dizem que, sem partidos políticos, não pode existir democracia, enquanto outras dizem que a democracia pode funcionar sem partidos. Qual dessas afirmações se aproxima mais da forma como você pensa? 1) Sem partidos políticos, não pode existir democracia; 2) A democracia pode funcionar sem partidos”.

7. No banco do CESOP-Datafolha (1993), a questão original é "Você está totalmente satisfeito ou totalmente insatisfeito com a maneira como a democracia está funcionando no Brasil atualmente? Numa escala de 1 a 10 pontos, em que 1 significa que você está totalmente insatisfeito e 10, que está totalmente satisfeito com a democracia no Brasil, que nota você dá a ela”. A codificação da equipe do Procad alterou a escala para $1 / 2=0 ; 3 / 4 / 5=1 ; 6 / 7 / 8=2 ; 9 / 10=3$. Nos bancos do Latinobarômetro (1995-2018), a questão é "Em geral, diria que está nada satisfeito, pouco satisfeito, satisfeito ou muito satisfeito com o funcionando da democracia no Brasil? 0) Nada satisfeito; 1) Pouco satisfeito; 2) Satisfeito; 3) Muito satisfeito.

8. Os modelos completos, com as estimativas de efeitos dos controles, podem ser obtidos com a execução do script disponibilizado na página eletrônica do Grupo de Pesquisas Cultura Política, Comportamento e Democracia (https:// cpcduem.wixsite.com/cpcd-uem).

\section{Referências}

ARRETCHE, M. Democracia e redução da desigualdade econômica no Brasil: a inclusão dos outsiders. Revista Brasileira de Ciências Sociais, São Paulo, v. 33, n. 96, e339613, 2018. https://doi.org/10.17666/339613/2018

BARBOSA FILHO, F. H. A crise econômica de 2014/2017. Estudos Avançados, São Paulo, v. 31, n. 89, p. 51-60, jan.-abr. 2017. https://doi.org/10.1590/s0103-40142017.31890006

BOOTH, J. A.; SELIGSON, M. A. The legitimacy puzzle in Latin America political support and democracy in eight nations. New York: Cambridge University Press, 2009. 
CASALECCHI, G. Legado democrático e apoio à democracia na América Latina: evidências e mecanismos explicativos. 2016. Tese (Doutorado em Ciência Política) - Programa de Pós-graduação em Ciência Política, Universidade Federal de Minas Gerais, Belo Horizonte, 2016.

CLAASSEN, C. In the mood for democracy? Democratic support as thermostatic opinion. American Political Science Review, New York, v. 114, n. 1, p. 36-53, 2020. https://doi.org/10.1017/S0003055419000558

CONVERSE, P. E. Change in the American electorate. In: CAMPBELL, A.; CONVERSE, P. E. (eds.). The Human Meaning of Social Change, 1972. P. 263.

DAHL, R. A. Poliarquia: participação e oposição. São Paulo: EDUSP, 2005.

DALTON, R. J. Democratic challenges, democratic choices: the erosion of political support in advanced industrial democracies. Oxford: Oxford University Press, 2007.

DALTON, R. J. Political realignment: economics, culture, and electoral change. Oxford/New York: Oxford University Press, 2018.

DELLI CARPINI, M. X.; KEETER, S. What Americans know about politics and why it matters. New Haven/ London: Yale University Press, 1997.

DENEMARK, D.; MATTES, R. B.; NIEMI, R. G. Growing up democratic: does it make a difference? Boulder: Lynne Rienner, 2016.

DUQUE, D.; SMITH, A. E. The establishment upside down: a year of change in Brazil. Revista de Ciencia Política, Santiago do Chile, v. 39, n. 2, p. 165-189, 2019. https:// doi.org/10.4067/ S0718-090X2019000200165

EASTON, D. A systems analysis of political life. New York: John Wiley \& Sons, 1967.

ERIKSON, R. S.; MACKUEN, M.; STIMSON, J. A. The macro polity. New York: Cambridge University Press, 2006.

FERES JÚNIOR, J.; KERCHE, F. (orgs.). Operação Lava Jato e a democracia brasileira. São Paulo: Editora Contracorrente, 2018.

FUKS, M.; CASALECCHI, G. A.; ARAÚJO, M. M. Are dissatisfied democrats critical? Reevaluating the concept of the critical citizen. Opinião Pública, São Paulo, v. 23, p. 316-333, 2017. https://doi. org/10.1590/1807-01912017232316

GLAESER, E. L.; PONZETTO, G. A. M.; SHLEIFER, A. Why does democracy need education? Journal of Economic Growth, Boston, v. 12, n. 2, p. 77-99, 2007. https://doi.org/10.1007/s10887-007-9015-1

HELENE, O. The evolution of expected schooling in Brazil in the 20th century. Educação e Pesquisa, São Paulo, v. 38, n. 1, p. 197-216, mar. 2012. https://doi.org/10.1590/S1517-97022012005000005

HUNTER, W; POWER, T. Bolsonaro and Brazil's illiberal backlash. Journal of Democracy, Washington, v. 30, n. 1, p. 69-82, 2019.

INEP [Instituto Nacional de Pesquisas Educacionais Anísio Teixeira]. Pisa 2000 - relatório nacional. Brasília: INEP, 2001. Disponível em: www.inep.gov.br/internacional/pisa/. Acesso em: 29 jun. 2001. 
KRISCHKE, P. J. The learning of democracy in Latin America: social actors and cultural change. Huntington: Nova Science Publishers, 2001.

LIMONGI, F. O passaporte de cunha e o impeachment: a crônica de uma tragédia anunciada. Novos Estudos CEBRAP, São Paulo, v. 34, n. 3, p. 99-112, 2015. https://doi.org/10.25091/ s0101-3300201500030005

MATTES, R. B. et al. The limited impacts of formal education on democratic citizenship in Africa. Rondebosch: Centre for Social Science Research, 2009.

MCCOY, J. L. Political learning and redemocratization in Latin America: do politicians learn from political crises? Florida: North South Center Press/University of Miami, 2000.

MELLO, G.; WELLE, A.; OLIVEIRA, A. L. A crise prossegue: baixo crescimento e alta desigualdade no Brasil pós-recessão. Nota do Cecon, Campinas, n. 3, maio 2018.

MOISÉS, J. A. Os brasileiros e a democracia: bases sócio-políticas da legitimidade democrática. São Paulo: Ática, 1995.

MOISÉS, J. A.; MENEGUELLO, R. A desconfiança política e os seus impactos na qualidade da democracia. São Paulo: EDUSP, 2013.

MORETTIN, P. A. Modelos para previsão de series temporais. Rio de Janeiro: IMPA, 1981.

NORRIS, P. Critical citizens: global support for democratic government. Oxford (UK)/New York: Oxford University Press, 1999.

OLIVEIRA, R. P.; ARAUJO, G. C. Qualidade do ensino: uma nova dimensão da luta pelo direito à educação. Revista Brasileira de Educação, Rio de Janeiro, n. 28, p. 5-23, abr. 2005. https://doi. org/10.1590/S1413-24782005000100002

OSBORNE, J. W. Best practices in quantitative methods. Thousand Oaks/Calif.: Sage Publications, 2008. RIBEIRO, E. A.; BORBA, J.; FUKS, M. Contexto democrático, tolerancia escolar y política en América Latina. Revista Latinoamericana de Opinión Pública, Salamanca, v. 8, n. 1, p. 11, 2019.

RUSTOW, D. A. Transitions to democracy: toward a dynamic model. Comparative Politics, New York, v. 2, n. 3, p. 337-363, 1970. https://doi.org/10.2307/421307

SAMPAIO, G. T. C.; OLIVEIRA, R. L. P. Dimensões da desigualdade educacional no Brasil. Revista Brasileira de Política e Administração da Educação, Brasília, v. 31, n. 3, p. 511-530, 2015. https:// doi.org/10.21573/vol31n32015.60121

SANTOS, W. G. Razões da desordem. Rio de Janeiro: Rocco, 1993.

SCHLEGEL, R. Educação e comportamento político. Os retornos políticos decrescentes da escolarização brasileira recente. 2010. Tese (Doutorado em Ciência Política) - Faculdade de Filosofia, Letras e Ciências Humanas, Universidade de São Paulo, São Paulo, 2010.

SINGER, A. Brasil, junho de 2013, classes e ideologias cruzadas. Novos estudos CEBRAP, São Paulo, n. 97, p. 23-40, nov. 2013. https:// doi.org/10.1590/S0101-33002013000300003 
SINGER, A. O lulismo em crise: um quebra-cabeça do período Dilma (2011-2016). São Paulo: Companhia das Letras, 2018.

SOMMET, N.; MORSELLI, D. Keep calm and learn multilevel logistic modeling: a simplified three-step procedure using Stata, R, Mplus, and SPSS. International Review of Social Psychology, London, v. 30, n. 1, 2017. http://doi.org/10.5334/irsp.90

SOROKA, S. N.; WLEZIEN, C. Degrees of democracy politics, public opinion, and policy. New York: Cambridge University Press, 2010.

SUNSHINE HILLYGUS, D. The missing link: exploring the relationship between higher education and political engagement. Political Behavior, New York, v. 27, n. 1, p. 25-47, 1 mar. 2005.

TATAGIBA, L. 1984, 1992 e 2013. Sobre ciclos de protestos e democracia no Brasil. Política \& Sociedade, Florianópolis, v. 13, n. 28, p. 35-62, 31 dez. 2014. https://doi.org/10.5007/2175-7984.2014v13n28p35

TORCAL, M.; MONCAGATTA, P. Political support. In: BADIE, B.; BERG-SCHLOSSER, D.; MORLINO, L. International Encyclopedia of Political Science. Thousand Oaks: SAGE Publications Inc., 2011.

VELOSO, F.; ARAÚJO, A. Educação básica no Brasil: construindo o país do futuro. Rio de Janeiro: Elsevier/ Campus, 2009.

VERBA, S.; SCHLOZMAN, K. L.; BRADY, H. E. Voice and equality: civic voluntarism in American politics. Cambridge (MA): Harvard University Press, 1995.

WLEZIEN, C. The public as thermostat: dynamics of preferences for spending. American Journal of Political Science, Hoboken, v. 39, n. 4, p. 981-1000, 1995. https://doi.org/10.2307/2111666

\section{Sobre os Autores}

Julian Borba é professor do Departamento de Sociologia e Ciência Política da Universidade Federal de Santa Catarina e Pesquisador do CNPq. Doutor em Ciência Política pela UFRGS. Pesquisa na área de atitudes e comportamento político.

Ednaldo Aparecido Ribeiro é Formado em Ciências Sociais pela Universidade Estadual de Londrina e Doutor em Sociologia pela Universidade Federal do Paraná. Pesquisador bolsista produtividade do CNPQ na área de Comportamento Político.

Recebido: 01 jul. 2020

Aceito: 10 nov. 2020 